\title{
Tricia Rose Interviewed by George Lipsitz ${ }^{1}$
}

\author{
Tricia Rose Interviewed by George Lipsitz: Click for Video.
}

George Lipsitz: I'm George Lipsitz and I'm here today with Tricia Rose. We're speaking for Critical Studies in Improvisation, and we want to discuss the relevance of Tricia's work and career for the study of improvisation and, we hope, get to some broader issues about what it means to study culture in a social context? So Tricia, if you could get us started, maybe recapitulate how you came to study forms of expressive culture that had not been widely studied before. What were the methods that you had to develop, and what have been the challenges of that work?

Tricia Rose: Yes, well thanks George for doing this with me, and it's been a long time coming for us to sit down and have a conversation about the kind of work we try to do and why it matters and why expressive culture is an important place to understand what's possible, not just what is, or what's fun. So, as you know, because you knew my work from the very beginning, I was fascinated by hip-hop as a social form that came into existence in my lifetime. That is to say, I'm old enough, tragically, to be able to say I know what black music sounded like before hip-hop. And what that means is I was able to sort of see it as an artistic expression, but also as something deeply rooted in social institutions, in a good way and in a bad way. Right? That is to say, a lot of what made hip-hop come into existence was the result of amazing technological advances, but it was also the result of male-centred apprenticeship that made it hard for young girls to break in; and most importantly, it was very significantly a kind of cultural response to extensive fragmentation of community that deindustrialization and gentrification and, the kind of "final nail in the coffin" of black urban communities that was taking place in the 1970s. And so, in a funny way, it was all about seeing advantages in fragmentation, trying to find ways to connect when that mattered more, using musical traditions even when they had been discarded, but also sometimes not showing them requisite respect because of course there wasn't much respect. So part of it for me was really just discovering the complexity of both the joy and beauty, and the kind of sadness and limitation that the art form represented.

And, later on in my career-I try to use the analogy of chitlins: you know, when people want to tell you how great chitlins are! My feeling about that is if the pig couldn't digest it, I'm not sure l'm in the business of working on eating it! But it's a high art form to make it digestible, but we shouldn't actually look for that. Right? We shouldn't limit ourselves and say, "well, this is this high art form, let's all eat chitlins." What we should say is well, the high art form had to work itself out on the intestines of pigs, but the art form is separate from that context and that's what we should carry forward and raise the question: well, why were we only eating pig guts? What was the context? So that kind of tension in hip-hop was always important to me. As a result, my work is often about hip-hop, but not really just about hip-hop. And in that sense, I'm really trying to address something that I think is bigger and more important than any single art form that we could study.

GL: In order to approach hip-hop in that way, you had to see it and register changes in a broad social field, or maybe in a number of different social fields. And it seems to me that there must have been something in your experience, in your entry to it, things that you saw with your own eyes that convinced you that it had that meaning. Because, for many people, it came to them as a commodity packaged in the way that other commodities did. It came to them as a stylistic innovation, and to imagine the broader social world behind it didn't seem necessary. But why was it necessary for you?

TR: Wow! George, that's a good question. . I always saw individual human interaction in a context. I always asked that question. My mother tells a very funny story when I was very little about something that was going wrong in our neighbourhood. I'll spare our viewers and listeners the details, but I grew up in Harlem: at this point it was the late 1960s and something bad happened. First, I was sad about what happened, but then my mother said I kept asking "why, why, why, why, why?" I haven't stopped asking! l'd say, "but why though, was this the case?" Why? So eventually we got to things like racism in a general sense, or lack of affordable housing, or unjust treatment by landlords, or whatever the situation was, and I was like "well, why do we let this happen?" And that kind of personality, that I'm not responsible for, I think I just came with that approach, but it was also cultivated by drawing connections that drew my ear to music. I was always a very musical kid, and that made me think about what was happening in these creative moments: what seemed possible and how things were possible.

There's another really funny story l'd love to tell you about my dad. So now l'm a teenager: roll forward and we're in some big Ford LTD, green. It's like the size of a house and we're strolling down somewhere in the Bronx, and McFadden and Whitehead "Ain't No Stoppin' Us Now" comes on the radio. And gosh did I love this song! And I'm a young person, and this is my generation, and here is my dad, and what does he know? He's an old guy-and God knows he wasn't that old [laughing], in retrospect. And I'm like "this is the next generation, this is cool, and I love this song." And he said, "Well, what do you think it means?" And I said, "Well, you know, it means I can do this, and I can do that." And he says, "Well, why did they say us?" And it was like the whole world stopped. And I said, "Why did they 
say us?" And he thought, whoa, she's asking a question for a change-teenagers don't ask too many questions, and he said, "Because it's really a statement. Yes, it's a fun song about a good time, but it's also about the idea that a group of people are unstoppable and that we're on a roll to make the kind of changes we want to make." And he started talking about the civil rights movement-and I will never forget that moment.

It all made so much sense, because even my pleasure in the song was attached to an incoherent feeling about that that was produced in my community, but that there really was no language for in the curriculum or any of the schools I went to help me understand. That's what these songs are trying to do. Tell a story that allows us to enjoy the individual moment: there's no stopping me in my goal to do whatever, but there's no stopping us if we understand ourselves in a certain way. And I think those kinds of experiences on the ground and my own background and circumstances really encouraged me to keep asking those kinds of questions.

GL: And I think your work radiates with that sensibility. That whether you're talking about music or interpersonal relation or you're discussing the journalistic and political fights over music, you find archives that other people haven't investigated, and you see them as sights and sources of knowledge, as repositories of collective memory, as sights of moral instruction, as ways of calling communities into being through interaction and through performance. When you were studying these things in an academic context, the archives are often fairly carefully delimited: musicology studies one set, sociology studies another, history studies another. There must have been a clash between your sense of these rich sources of knowledge and the focus and the methods of individual disciplines.

TR: Well, it was not a clash-they were impossible! It was worse than a clash. A clash would suggest they had run into each other! [laughing] They didn't, but you know, and I do this not because we're having this interview, but because it's true: and that was, had I not had the luck to run into you and begged the department to bring you to Brown, literally, I don't think I would have resolved that problem. Your own work and your belief in what I was trying to do really made it possible, without a doubt. Now, certainly I had intellectual training here at Brown and I learned a lot from my mentors here, but that idea that these things go together, that how they are lived matters more than the disciplinary separations that we've created on top of them, was something that higher education often trained you out of believing: that we know something they don't know. Now of course, we know different things and we should appreciate what we know and help the world with it, but there are also ways of knowing that come from understanding how connected lived experiences are to one another, whether they're musical, economic, social, gender, political, religious, and that those things are [as] intertwined and mutually reinforcing as the context for understanding them. Not as what makes them messy, not as what makes them unruly, but what makes them what they are.

And so you know, really, you were being a very strong booster before I knew what the heck I was doing was like, "Oh, I guess somebody thinks this makes sense!" I was like, "Oh hey! I've got a church of one! l've got a congregation of one; I'm going to take it!" That really was very important, but to be honest, what I brought to your enthusiasm (because of course you weren't here, so I had to hold onto something while you were back at your own university) was a real sense that I wasn't doing this work to fit into a discipline. My drive was to answer questions that seemed really important to me, like how do people make culture, develop progressive, useful forms of agency, under very difficult structural conditions? What works? What doesn't work? How do the things come together? Which is what is so exciting and unpredictable. And what are the ways in which we can either aid or make invisible these varied activities and practices? And so that drive-that question-is what drove me. And I think, if you remember, I almost went on to law school halfway through graduate school, because I thought, "Gee, you know, academia seems so removed from the things I was most interested in." But I think ultimately I was happy to stay because I realized that forcing our minds on these broader social questions is what African American studies, of much of Area studies, have been about: forcing the academy to attend to the political nature of knowledge. So that, I think, is what forced me out of the mentality "I have to fit this into a music department; I have to fit this into a semiotics context; it can only be cultural studies; or it's just black studies or it's feminism." But all this to say these things are really interlocking.

GL: Well, I think that your work has helped show people how this can be done, and it not only challenges the credentialed archives with alternative archives, but it also has an emphasis on practice and participation that I don't see in a lot of scholarship on culture. You know, you talk about how people make meaning for themselves. Often in arts criticism, not just in the academy, but everywhere, there is an emphasis on the created object rather than the creative act. And then creative actors are often seen to be solitary geniuses or eccentrics rather than people participating in a broader social realm. And I wonder again, if you could be self-reflexive and see if there are things in your own experiences as an artist, as an athlete, as an academic, that have encouraged you. As somebody who has done political work and knew people at housing projects from your work with the City when you were in college, I wonder if there is a way to account for this emphasis on the knowledge of participants and the importance of practice in your scholarship. 
TR: Mm, yes, I appreciate that. Well. . I think that the combination of. . . before I was going to be a lawyer, before I was going to be an academic, I was going to be a singer! I was a musician. I studied music for a long time, and I was actually torn a lot between improvisational-like traditions, or traditions that seemed to have no rules. And of course they had elaborate rules that nobody ever talked about, and traditions that had very strict rules musically. And I always found the moment of hearing something interesting and figuring out how to make it your own and be in dialogue and to make people interested in what you're doing by connecting with what they're already hearing, and what they know to be a really exciting moment. Because that moment between taking what's commonly known and what you're bringing to that knowledge is the moment of continuity and change simultaneously. And I don't think total change is actually all that exciting -it's mostly terrifying! Nobody wakes up and says, "I don't want to know anything about today and I don't want anything to be familiar," you know? And then on the other hand, you need to be able to be flexible and to have surprises be generative. And so that connection was already interesting. And I think as you mentioned with sports, I had a very similar experience: I played a lot of pickup basketball long before certainly a lot of girls played basketball, way before the WNBA. It's a good thing they didn't have that: I might not be there! [laughing] They might have rejected me, but I would have kept trying!

GL: I think of you as still setting a pick for us at the free-throw lane of life.

TR: Oh, well, thank goodness, thank goodness. And I took the charge, and I went down, and I stayed down if I needed to. But certainly the way African Americans play basketball, which is a cultural approach to the sport, meant that you had to figure out what the conditions were right now. You couldn't make a decision before it was time to make the decision. And that was really like a second or two before it happens. So the more you can see things in process on their way, arcing, showing up at the moment where something's going, not sort of being here where it is, is a way of thinking and a way of responding that is really exciting to me and interesting. And I approach ideas that way. I think, really, we should treat questions and answers as improvisational thinkers, which means we use the body of knowledge we have to think creatively about putting pieces together in ways that generate something new and interesting; not just, you know, for the sake of it, but because they tell us something. So that's really been a really important part of the way l've tried to do the way I do whatever I'm doing. It's not sort of conscious; it's sort of what I favour. And I think that's what always made music and sports and human activity in groups particularly exciting. I'm not a fan of art that's entirely, personally, individually constructed and doesn't speak to something broader. Of course, Morrison and Ralph Ellison and others are doing individual work, but it's about something that's examining a broader community and that, that's always been really, really, important to me.

GL: Yes, well, this sense of the way you need to improvise on a basketball court, where you need to be fully aware of what's around you and you have to seize opportunities when they come up and be prepared for them: Stokely Carmichael always used to say that "you have to be ready, because if you can be ready then you don't have to get ready."

TR: Right.

GL: And so a lot of our reading, our studying, is in some ways trying to be ready to say the right thing, at the right time: certainly teaching is like that as well. And I think for this, for the use of this journal, this take on improvisation is tremendously important because improvisation is often presented to people as a kind of individual freedom in which social connections are not necessary. And yet, I remember in Black Noise, one of your first contributions to original discovery scholarship was showing how the rupture in the lives of black youths gave them an advanced sense of rupture in culture and in music. Because learning, preparing to be interrupted and preparing mastery and responding to interruption, was a survival skill, and part of the way that was taught was in the art. And so I wonder if you could talk about these contradictions in improvisation: that when we use the words and talk about it some people mean the opposite of what we're saying.

TR: Mm, yes. That's really, really quite true. I do worry about . . I mean although improvisation as a field is crucially important, because it forces us out of certain kinds of disciplinary boundaries, it's a way of thinking or a way of acting that should transcend art forms or even historical disciplines, philosophical discipline, et cetera. But. . . that said, sometimes even the most generative categories can be pressed into the most non-generative service. Right? So improvisation isn't the way out. Improvisation in the right hands is a tool to imagine a way that hopefully is a way out, based on what we put into it. So it's really about what you put in on the front end, and in that sense, to go back to the question of the ruptures of urban life in the 1970s for young people of colour, is that it was a kind of pinnacle of a long period of constant ruptures, really. I mean, if you think about the history of various forced and then chosen migrations of black people, and living under conditions of enormous uncertainty and constant changing circumstances that were outside of your control, but for which you had to make sense in order to survive, it turns a certain kind of improvisational thinking into a high art form because it literally is about survival. And the communal spirit of which many African diasporic cultures come, while changing dramatically and changed dramatically through the Middle 
Passage, nonetheless confirmed the idea that the collective is bigger than the individual and that as a musical practice, that as a religious practice, that as a lived experience practice, as a high art value-l'm sorry, as a high social value-I think, really retains itself as a key principle in African American culture. Now, that said, whether or not the academic circles in the U.S. can properly appreciate the ways in which black cultural improvisation specifically gives us the progressive frameworks through which we understand the value of improvisation: that l'm not sure. So there's a sense in which I think people have sort of, by severing it from those histories, they've been able to say, "well, we'll leave the black off and just call anything improvisation, no matter how narcissistic, no matter how navelgazing, no matter how personally invested and sort of additive to freedom on top of freedom on top of freedom." For me. . . that's the worry I have. That kind of severing has unfortunately allowed people to use the language of black improvisation without acknowledging the traditions of suffering and creativity. There are terrible things that have gone on. Right? But those artistic traditions have literally been a rather crucial way of life.

GL: Yes, I think, for you and me this is a key issue that the artistic form, the ideas of political organization and community and spiritual and moral teachings that we respond to are not just incidentally or ecologically located by dark skins. That they come from history, as our friend Robin Kelley says, "not from shared bloodlines, but a history of shared bloodshed." And that in fighting for survival, the miracle of survival of black people in America, which is unaccountable by normal circumstances, and add to that the miracle of black humanity and black democracy, is what people can learn from; but not-it can't just be freely appropriated outside of the context that gave birth to it. And so, the blackness has to do with struggle in a precise historical moment that is useful to all people in all moments, but needs to be understood as a particular response.

TR: Right. Your work is such a great example of this because at every moment that you attempt to illuminate the specificity of blacks, it's never essentialized nor severed from the historical experience, and always placed in service of a broader human good. Right? Which is of course what most black cultural contexts were doing anyway: God forbid-but that drive to say, without heavy romanticization, but with appreciation, I'm going to connect these traditions to a broader social world and force everyone out of their imaginary comfort zones, which is some sort of little permanent black universe that never was-that no one else had ever seen-and in fact is completely constructed by the world we know. Nor are you saying there's this other dominant society that's all the way over here, that shouldn't be intersected. So that, that togetherness. . . and reciprocity, and the balance of it has been very powerful to me for a very long time. And, that said, I think we're in a very strange moment George. The trajectory of the study of expressive culture, the trajectory of the study of African American culture, has really been, I think, stymied by a fear that by naming it as black in some way, that it is being claimed to be biologically black (as you make reference to there), but also fixed, segregated, and sort of claiming its own inferiority. Right?

GL: And the private and personal parochial concern of black people themselves, and not generalizing it to the proper circumstances.

TR: Right! Right! Which is so ironic. Right? Because of course we think we can export democracy to the entire world as a neutral phenomenon and imagine that everybody should be excited about it and not feel like they're being given an imperial project; but we can't export black culture across the street without being accused of somehow being parochial, or somehow being universal. So the very racialist discourse that got us here traps even the radical tradition in the academy today in a way that I think is very troubling. It's either that it's aestheticized so there are no bodies at all. You have blackness with no black people: you have cultural traditions with no context for them to have come into existence, and that can only be understood in ways that make black people irrelevant or invisible, and almost too black to be addressed.

GL: Yes, well, one of the things that you do with that conundrum is to find within black culture the many ways in which refusal of the slave-human binary has produced an ethic of love and an ethic of mutual recognition. And I think you pick up here on things that James Baldwin and others have seen as central: that we're not just talking about a legacy of suffering and pain. We're talking about, as you say in a forthcoming piece, about Lorraine Hansberry and the ability to find something left to love in people whose circumstances may have crafted to be unlovable, and in ourselves as well as in others. Baldwin says that this is really the world held together by the love of a relatively small number of people; and yet, that love is tremendously important. In the letter he writes on the 14th birthday of his nephew, he says, "when you came into the world we wondered if it was right for you to be in the world. Was it right to bring another baby into the world?" And he says, "we were trembling then, but we have not stopped trembling yet, but if we had not loved each other, none of us would have survived." Now, you take love in your work seriously, in a way that for reasons that we understand, many critics shy away from. You know, because there's a sentimentality of love, because there's a confusion of love with simply erotic or phileo love; and yet, you argue that as a survival mechanism and an epistemological source and as a critique, that love is very important and very valuable, particularly in the discussions of intimate and interpersonal relations that you've worked on for so long. And I wonder if you could talk 
about why love matters in those ways and why it's important to rescue it from the banal uses of the term that permeate our society.

TR: Phew, that's a lecture in its own right there, George! Phew, that's an incredibly well-crafted thing. . . Well, I learned this kind of the hard way. . . which is that I realized that a certain kind of aggressive, public sphere-limited political demand, anger-infused politics-wasn't really going to get me anywhere. You know?

GL: Because it could easily be limited to a public display. . .

TR: For a few things! Well, one: it only addressed the aggressor. Right? It meant that, as a woman even, it would have to be an angry confrontation with men.

GL: It centres them.

TR: It not only centres them, but it asks the question: what am I going to do with who I care about? What am I making? Not, what am I unmaking? It doesn't move to the question after you've burned everything down. I have to tell my students: okay, so we have the revolution you asked for. Here's the match, here's the lighter fluid, we got the whole thing. So we burned it all down, and now, what's the story now? All the energy you've been spending on intending the burn down, you've now asked the question: what are we going to make the day after? And then we'll simply have chaos. I'm not saying you do nothing, but we should be asking and living the future as much as we can, because we have to figure it out. And the more we figure it out now, the better we are. For me, it was a realization that these movements without a love ethic can literally destroy people. Right? It was a real sort of recognition on that level.

That was one; now number two: black music has always been very smart on this question. Most people who want to write on black music write about the protest: they write about the improvisational solo in someone's [music, like] Coltrane, or they write about male rappers. But it's the love ethic in black music that makes it the most sustaining, most empowering thing in Western music, if you ask me. I know I'm a little biased but it's the thing that never gets written about. Why are those songs so radical? They're radical because black bodies are so unloved and so hated and so mistreated for so long that for people to sing to each other with so much care and so much tenderness and so much humour and so much banter and talk and freedom and play is like a bomb. You know? And that, to me, is what the love ethic is all about. It's about not denying the context, but taking into account, but not being limited by it. That is to say the love song isn't about the oppressor; the love song is about whoever is in the community of any background, who is stuck down here with us. Right? And that's what those songs mean. It doesn't mean I want to get into your pants - although many of them also mean yes, l'd love to get into your pants. There's an "I want to get into your pants" tradition. That exists. There's nothing wrong with that as long as everyone's in agreement! But that's not what most of those love songs are about. It's about a kind of care and appreciation and affirmation that makes it just the richest love songs we have in American popular culture.

So I think that Baldwin's claim there, which is my favourite essay of all time, you just happened to mention, along with, as you mention l've been trying to deal with around Hansberry, is an attempt to resuscitate what has been a love ethic tradition we know came. Right? We know Fannie Lou Hamer, we know a lot of people who were involved on the political front. But in the cultural arena, there's a long tradition of artists trying to tell people, not just black Americans, but tell people that this is a tradition that saves us. This is a tradition that gives us a place to build, not just a place to tear down. And we got very angry about hearing that, and I think we need to bring it back. I think there's an enormous amount to learn, particularly now, when everything is being predatorily consumed.

GL: Oh yes, and the idea of anything motivated by something other than fear or avarice is kind of off the table. So it's all the more important to hone those traditions.

\section{TR: That's right.}

GL: A final question about your work in improvisation. It seems to me that you've not only written about improvisation, but that every project you've had has responded to a particular opening, to a particular historical moment, even when other people didn't see those as openings. But you have a sense of. . . I don't think we could have talked to you in graduate school and gotten about a list of the next five books because so much of what you have done has been dialogic. It's grown out of responses to your work, but it's also grown out of your. .

TR: Changing conditions! 
GL: Changing conditions and your deep involvement in black communities around this country and your insistence on talking to people and finding out how they make meaning for themselves and how they live, and I wondered if you could tell me about, at this moment, the projects that you have: how do you see them as improvisations necessitated by current conditions?

TR: Well, I really appreciate that! I'm glad this is all on tape so I can go ahead and give it to someone for some reason! I really appreciate that. I do! I think that ideas come to me that way. They really do. If I'm not really excited about writing about it, it doesn't happen. I'm not the type to write an essay for this or that reason. It's either I'm interested, or I'm not. And. . . about shifts in dynamics that catch my eye in a particular way. And when they give me that sense that, "wait a minute, something's really afoot here", then I really dig in and try to figure it out. And of course I want to ask people, or do internet: whatever kind of research to figure out where people are, because they're in the moment, but I also want to bring what I know about how these structures are moving in very invisible ways to create the kinds of conditions that l'm attending to. So it's really this kind of process for me. It's really a top-down, a bottomup, a real amalgamation. And. . .

\section{GL: And when you're involved, it changes too.}

TR: Absolutely! Absolutely. I mean, the piece I just did on the Kelley Williams-Bolar case, the woman in Ohio that was jailed for sending her children to a school in an all-white district, in a state that's supposed to have open enrolment state-wide, really made me think about the politics of this kind of extension of the narrative criminalization for families, for black mothers and for communities. To steal education: that that isn't just an extension; it's also a reformulation. At the same time as it takes criminalization and pushes it out, it also changes what we can understand as non-criminal black behaviour. There's almost nothing left. Right?

\section{GL: A mother trying to get her children a decent education becomes a theft.}

TR: Absolutely. Right, the cultivation of private property. . . So for me, that moment in every step has been about trying to illuminate, to make sense of a moment and a condition that has the possibility of being either more devastating or to be a way out. And to try to shed some light on it with what I can bring to it.

But the book I'm trying to work on now-I use the word trying because, you know, running a centre [the Center for the Study of Race and Ethnicity in America] is a fulltime job_-it really speaks to the first set of questions you asked me: which has to do with the way in which we have historically understood African American culture as largely a culture that stood in resistance to, in opposition to a dominant culture framework. Right? The legacy of slavery and Jim Crow and segregation produced a relatively isolated space. Right? To produce alternative consciousness, radical traditions, et cetera. Devastating as they were, they had an upside with that kind of continuity. But what's happened in the last 30 or 40 years is the downside of racist integration, or what I call "inclusive discrimination" (which is a phrase I'm trying to work on): it's like, what's the point of this? Leave me out here and discriminate. l'll be alright. But what that has done is that it's really eroded the assumption that we used to be able to make about black creative spaces being oppositional to a dominant cultural framework. But we don't have an intellectual tradition that's well established raising that question. Right? What we have is a lot of people saying, "Lil Wayne is a radical, you know, an oppositional thinker. . because he's Lil Wayne and he's black and rap is this from 1987, and that's where we are." And so there isn't a real challenge to say, well, "if the conditions that created a radical tradition are largely gone, and if a whole new generation of young, black people are coming of age in a consciousness in which they think they are the mainstream in a very complicated way, that there is no sell-out, because the market is who we are. What happens to a black radical tradition and where do we look for it?"

I didn't say it didn't exist, but we can't assume that it's permeating the world. It's not just about black culture, but that's what drove the project, which is about how predatory capitalism moved out of the financial markets and into the lives and consciousness of everyday people and has had a profound impact on who we are, not just how we bank, not just whether or not we're broke, but how we think about who we are. And if we don't pay attention to this problem, there might be not much left to work with. But at the same time, it also means it signals not to take care; but it also signals, hey, maybe we're looking in the wrong place by always looking to Beyoncé and Lil Wayne and Jay-Z. Maybe we should be looking to the people no one is paying attention to as much in the community-which is a whole lot of people-and that those communities are less celebrated, less market-invested spaces, and they are where the answers might be.

GL: Visibility is not justice. And visibility. . . for years we fought against invisibility, but visibility can be a tool against us as well. I think it was Ray Charles riffin' on the Ramones who said, "the danger zone is everywhere."

TR: [Laughing] Yes. 
GL: That's where we are. . . So, I think, you know, this is what I was looking for, and thank you so much for this. I think that the worldwide community of improvisation has gained so much from your work. I'm sure this interview will become part of their arsenal in trying to bring about a better world, and we look forward to where you take your improvisations in the future.

TR: Ah, yes, well we look much more forward to knowing where you're going to go, for sure! And I appreciate you coming, George, and for inviting me to do this. And I hope you have a part two! Because really, I should be interviewing you! I thought I was going to get to interview you! We should do this the other way next time.

GL: Every blockbuster has a sequel.

[Both laughing]

TR: Alright, thanks George!

GL: Thank you.

${ }^{1}$ Transcription by Rachel Shoup. 